\title{
INCOME DISTRIBUTION AND REGIONAL POLICY: THE CASE OF AP PALACHIA
}

\author{
William D. Gunther and Charles G. Leathers*
}

I.

The fundamental question examined by this paper is whether the size distribution of income in depressed areas is a factor of sufficient significance to warrant explicit concern in regional development policy. ${ }^{l}$ In the past, estimates of regional inequalities have explicitly focused upon differences in per capita income and unemployment rates, and regions, however large, have been viewed as homogeneous units with respect to these welfare measures. 2 While these indicators of economic welfare reduce a complex array of factors to several proxy variables, insufficient treatment of supplementary welfare measures is an unfortunate possibility. As Kenneth Boulding suggests, a dange $r$ with single numerical measures is that we tend to become obsessed with them. 3

To examine the distributional question more rigorously, estimates of the size distribution of income within Appalachia are developed and the signifiance of these results considered with reference to Appalachian Regional Development expenditures. The absence of any direct evidence on the subject of distribution equity in Appalachia implicitly suggests that eithe $\mathrm{r}$ (1) no substantial differences exist between the United States and Appalachia, or (2) that differences are not of special concern since they a re largely removed through the normal process of development. Each of these questions is examined in the following sections.

In 1960, the economic situation of the Appalachian region obviously demanded special legislative attention. Slightly more than twenty percent of the U.S. population received less than $\$ 3,000$ per year in 1960 , but thirtyone percent of the Appalachian population fell within this "poverty"level. The prosperity of the early sixties failed to have much impact on the region, and Appalachia continued to lag behind in United States.

While concern over poverty level incomes is certainly justified, the lack of explicit consideration of the total distribution of income could result in a paradoxical situation where absolute poverty has been reduced, but the inequality in the distribution of total income has become so severe as to impede the further development of the region. To examine the entire distribution question, however, requires measures of total income received by each income class, not just the number of individuals falling within the class. To arrive at measures of income received, several alternative estimates are developed below.

The basis of the regional income estimates are the Bureau of Census county data on the distribution of families, by income, by class, which a re then aggregated into a regional (Appalachian) distribution. Since the share of income received by each class is not available on a county basis, mean incomes are derived and used to estimate the total income received. Three separate estimates are presented.

* The authors are Associate Professor of Economics at the University of Alabama and Associate Professor of Economics at the University of Alabama. 
The initial estimate is based upon mean incomes derived from Internal Revenue Service data - total adjusted income for each income class in the nation is divided by the total number of tax returns filed. 4 Utilizing this data assumes that mean incomes for individuals in the same class are identical for Appalachia and the United States, further suggesting that the distributions of individuals within classes are similar. Given the characteristics of "depressed" regions, it seems unlikely that this assumption is realistic, partiularly at the upperincome levels, although it is impossible to determine the probable size of the error.

A second estimate is based upon the assumption that the means are assumed to be equal to the midpoints of the respective class intervals, (with the exception of the $\$ 15,000-\$ 24,999$ clas s and the over $\$ 25,000$ clas s). For the $\$ 15,000$ - $\$ 24,999$ class, a mean of $\$ 19,000$ is assumed, reflecting the likelihood that this class will tend to cluster toward the lower rather than upper limit. ${ }^{5}$ The open-end class of Over $\$ 25,000$ is fitted to a familiar Pareto curve, a method proven to be realistic for upper income ranges. 6 The mean income for this class is estimated to be $\$ 40,673$, over seven thousand dollars below the estimate based upon IRS data. While it cannot be proven, this change is felt to be in the direction of an improvement for the Appalachian estimate.

Finally, means are estimated upon a variety of assumptions for each of the income classes in order to allow the relative size of the income classes to play a role in the determination of the means.

First, it is assumed that the lower class interval can be accurately described by a log-normal function. Income classes above this level but below the open-ended top class are assumed to be described by straight line density functions: Finally, a Pareto function is again assumed for the upper class. On an a priori basis, these functions seem to provide a bottom basis for the determination of the means than the previous two estimates. To compare the effects of the three sets of estimates, a measure of the degree of inequality in each set of data a re developed.

To approach the distribution question succinctly requires a statistical measure of distributional inequality. Traditionally these measures have been oriented around the Lorenz curve and the Gini Index of Concentration. 7 While other measures are available and have various advantages over the Gini coefficient, the simplicity of this measure and the limitations of available data largely forced its selection in this study.

From the income distribution data bases on the first estimate of mean income (IRS data), the Gini coefficient for the Appalachian Region is estimated to be . 402. The Gini coefficient based on the second and third estimates a re .433 and .403 respectively. All a re reasonably close to each other. The comparable figure for the United States is .466 .8 Since a value closer to unity represents greater inequality, it appears that incomes a re less unevenly distributed in Appalachia than in the United States in 1959. Several brief comments on this finding are in order.

First, by the time Appalachia became a recognized "depressed" area in 1965 it is possible that this situation, if accurately described, had changed. Continued outmigration from the region may have changed the situation to such an extent that the distribution of income became less equally distributed. If this has occurred, than the widening gap between rich and poor regions is also being accompanied by a worsening in the distribution of income, a factor that may be of concern to regional planners because of its potential social impact. 
Table I. Estimates of Distributional Equity, State Regions of Appalachia, 1959

$\underline{\text { State Portion }}$

$\underline{\text { Gini Coefficient }}$

\begin{tabular}{ll} 
Alabama & .43 \\
Georgia & .40 \\
Kentucky & .50 \\
Maryland & .37 \\
Mississippi & .49 \\
Ohio & \\
New York & .37 \\
North Carolina & .34 \\
Pennsylvania & .42 \\
South Carolina & .35 \\
Tennessee & .40 \\
Virginia & \\
West Virginia & .44 \\
\multicolumn{1}{c}{ Mean } & .44 \\
\end{tabular}

Source: Computed from U.S. Bureau of the Census. U.S. Census of Population: 1960. Vol. 1, pt. 2, 12, 19, 20, 22, 34, 35, 40, 42, 48 and 50 . 
Secondly, the nature of the Gini coefficient does not allow one to draw significant conclusions regarding cardinal differences in the estimates. Given the limitations of the data and those of the technique, only large differences in estimates could be safely interpreted. Nonetheless, it is of some interest that our estimates did support the implicit assumption (assumed of Appalachian policy makers) that inequality does not appear to be a problem.

In treating the Appalachia region as homogeneous with respect to distribution equity however, we may be ignoring important intra-regional differences in the distribution of income. Since each state has some degree of control over funds expended in its Appalachian portion, it was felt worthwhile to explore state-to-state variations in the Gini coefficient. These estimates are derived by using the mean incomes for Appalachia as a whole for each of the state portions, and are presented in Table 1. Therewere considerable state-to-state variations in distributional equity, with a difference of 47 percent between the lowest (New York) and the highest (Kentucky). While the region may be homogeneous with respect to the level of per capita income, it is certainly not homogeneous with respect to the distribution of that income. Hence, if distributional equity is to be of concern to Appalachian regional development, it is farmore likely to be an intra-regional rather than inter-regional factor.

II.

In view of the substantial variations in the distribution of income within Appalachia, it becomes very pertinent to inquire into the possible redistributional effects of the public expenditures administered by the Appalachian Regional Commission. It must be immediately recognized that Appalachian funds do not constitute the total amount of public expenditures allocated to any a rea, and consequently the effects described are not necessarily those that would result if all funds were taken into account. Our limitedobjective is only to establish the direction of influence that ARC funds would have upon the distribution of income. In future workwe hope to measure the changes that occurred in the income distributions in the region between 1960 and 1970, and to evaluate the role played by regional policy in contribution to or countering the actual changes.

\section{PER CAPITA ARC EXPENDITURES AND INCOME DISTRIBUTION}

It is gene rally a rgued that distributional equity and the level of income are positively related. While this study does not seek to test this hypothesis, the framework can provide the basis for a discussion of ARC expenditures and their relationship to intra-regional distribution of income. Assuming such a direct relationship exists between public expenditures and distributional equity, it would follow that if distribution were a consideration in the allocation of ARC funds, they would be related to our measures of distributional equity. Due to the differences in population among the states, a per capita measure of ARC expenditures is more reflective of the intra-state allocation of funds.

In Table 2, the Gini coefficients, by state portion, are ranked in order of highest inequality to greatest equality, togethe $r$ with the rankings of per capita expenditures of ARC total funds. Using Spearman's rank-order correlation, there appears to be no relationship between distributional equity and the intra-regional allocation of ARC funds. $(\mathrm{R}=-.01)$. It appears that distributional questions were not an implicit objective of ARC policy during the period of time examined. 
Table II. Per Capita Allocations of Total ARC Funds and Non-Highway Funds, By State, 1965-1970

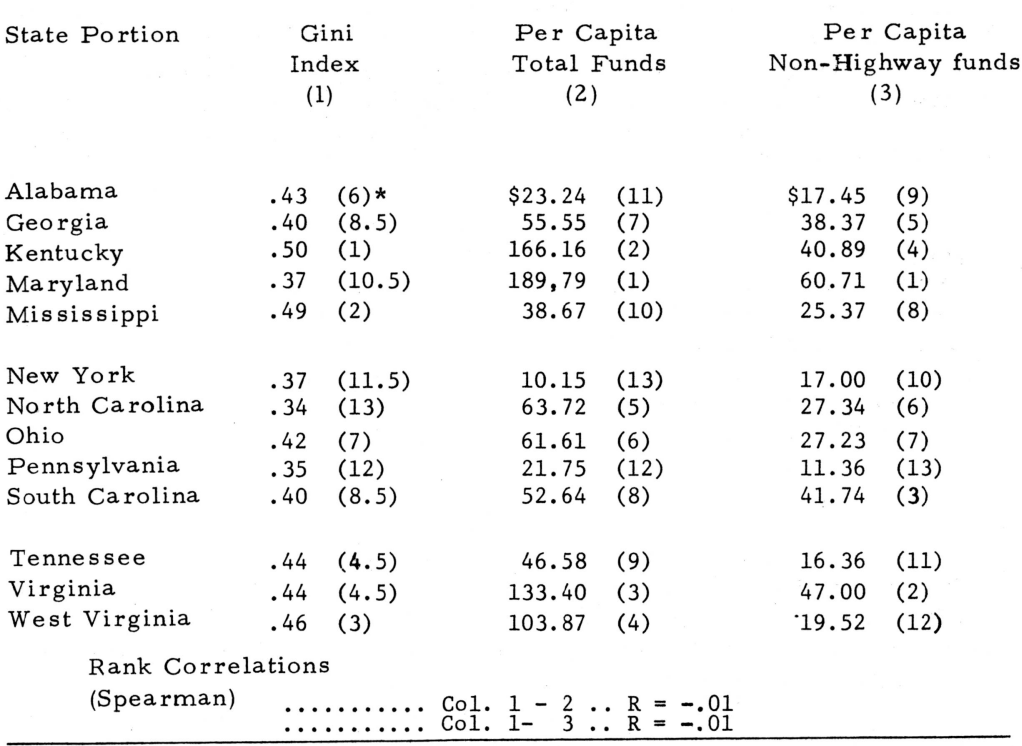

* Numbers in Parenthesis a re the ranks.

Source: Col. 1 from Table 5. Col. 2 and 3 from Robert D. Britt,"The Appalachian Regional Development Program, "Growth and Change Vol. 2 (July, 1971), p. 5, Table 2, and The Appalachian Regional Commission Annual Report, 1970 . 
It has been argued by Hansen and others, that the composition of public expenditures in Appalachia will affect the rate of economic growth. ${ }^{9}$ More specifically Hansen argues that social overhead capital investments (SOI), which are human capital development oriented, such as education and demonstration health projects, will have a more positive effect on economic growth than the economic overhead investment (EOI)p rojects such as highway development. Again, we do not attempt to validate or invalidate the thesis, although it has been noted recently that highway expenditures in Ozarka have had very little influence on the rate of growth in per capita incomes. 10 In the event that the thesis is valid, it behooves us to consider whether the SOI outlays have been allocated in such a manner as to have the greatest effect on income distribution even though total per capita expenditures have not. In short, have the largest per capita expenditures for SOI gone to the states with the highest Gini coefficients?

In column 3 of Table 2 per capita nonhighway expenditures are given together with their ranks. Nonhighway expenditures are being used as a proxy measure for social overhead investments (SOI). The rank-order correlation between per capita nonhighway expenditures and the measures of distributional equity is again extremely low. This again suggests that the portion of the ARC funds that would tend to have the greatest impact on distribution were not being allocated in such a way as to reflect an implicit or overt concern with distribution.

III.

It is recognized that these estimates are very provisional and do not reflect the entire picture for Appalachia. Other federal funds dealing with social overhead investments are made, in the region, and these funds may take the distribution of income more into account. Additionalevidence on the existing adequacy of suchitems as health facilities, vocationaleducation, and other SOI-type projects need to be taken into account in the additional allocation of funds. What is suggested by this brief excursion into the ARC expenditures is an appa rent lack of relationship between these funds and intraregional variations in the distribution of income. Whether or not this neglect is justifiable is a subject for much greater research, and a topic which we a re currently pursuing.

The purpose of this paper is mainly exploratory in nature. It is felt that a significant area, the distribution of income both between Appalachia and the rest of the U.S. and within the Appalachian region itself, has been a neglected factor in regional development policy. In view of recent social movements in the United States, this omission seems particularly glaring. While the available evidence on the degree of distributional equity in Appalachia is sketchy and subject to considerable degrees of interpretation, the meagerness of data should not blind us to the potential importance of the is sue.

What we have suggested in this paper is a tendency for the Appalachian Regional Development Act to ignore distributional equity, and possibly through a concentration of EOI projects, to foster tendencies toward greater inequality. Even those expenditures made in the SOI a rea a re not allocated to the state with the greatest inequality "problem". Since our limited evidence suggests that Appalachia had a greater degree of equality in the distribution of income than the U.S., such a tendency may be inconsistent with attempts to raise the overall standard of living of the residents. Additional evidence will have to be brought to bear on the question before any frim conclusions are possible. 
${ }^{1}$ For a discussion of the issues as they relate to the inclusion of distribution goals within nations see Social Policy and The Distribution of Income in the Nation. United Nations document ST/SOA 88, 1969. This has been an is sue of long concern to Simon Kuznets. See for example, his "Economic Growth and Income Inequality, "American Economic Review, 45 (March, 1955), pp. 1-28 and his "Quantitative Aspects of the Economic Growth of Nations: VIII Distribution of Income by Size," in Economic Development and Cultural Change II, Part II (January, 1963). Also see Nancy Baster, Distribution of Income and Economic Growth (Geneva: United Nations Research Institute for Social Development, 1970).

2 The issue of assumed homogenity of a region with respect to per capita income is discussed further in Arthur L. Wright and Melvin G. Blase, "A Depressed Region and Three Myths," Growth and Change. Vol. 2 (July 1971), pp. 14-22.

3"Fun and Games with the Gross National Product - The Role of Misleading Indicators and Social Policy, " in The Environmental Crisis ed. by Harold W. Helfrich, Jr., (New Haven: Yale University Press, 1970), pp. $157-170$.

4Internal Revenue Service, "Individual Income Tax Returns, 1960," Statistics of Income, 1960 , p. 87.

${ }^{5}$ U.S. Bureau of the Census, Income Distribution in the United States by Herman P. Miller (A 1960 Census Monograph). U.S. Government Printing Office, Washington, D. C., 1966, p. 215.

${ }^{6} \mathrm{~A}$ discussion of this approach appears in Maurice Liebenberg and Hyman Kaitz "An Income Size Distribution from Income Tax and Survey Data, 1944 , " in Studies in Income and Wealth, Vol. 13 (New York: National Bureau of Economic Resea rch, 1951), pp. 444-445.

${ }^{7}$ The Gini Index of Concentration is a summary measure of the familiar Lorenz curve. It is simply a ratio of the area lying between the Lorenz curve and the diagonal to the area under the diagonal. For a discussion of the limitations of the Gini Index, see George Garvey, "Inequality of Income: Causes and Measurement," in Studies in Income and Wealth, Vol. 15, (New York: National Bureau of Economic Research, 1952), pp. 27-47, and Martin Bronfenbrenner, Income Distribution Theory (Chicago: Aldine-Atherton, 1971), esp. pp. 43-50.

For simplicity, assume that the Lorenz curve is a series of straightline segments between any two points (giving rise to a series of trapazoids whose areas are given by $1 / 2 f\left(b_{1}+b_{2}\right)$, where $f=$ heights, and $y=$ bases $)$. The total area of all such trapazoids becomes

$$
\sum_{i=1}^{N} 1 / 2\left(f_{i}+1-f_{i}\right) \frac{\left(Y_{i}+Y_{i}={ }_{1}\right)}{2}
$$

For additional simplicity, the total a rea of the Lorenz Diagram is used, resulting in the following formula:

$$
L-10,000-i_{i=1}^{N}\left(f_{i}+{ }_{1}-f_{i}\right) \quad\left(Y_{i}+Y_{1}+{ }_{1}\right)
$$


For $\mathrm{n}>8$, the approximation is close. See U.S. Bureau of the Census, Income Distribution in the United States, by Herman P. Miller (A 1960 Census Monograph). U.S. Government Printing Office, Washington, D. C., 1966. pp 220-221; and Martin B ronfenbrenner, Income Distribution Theory (Chicago: Aldine-Atherton, 1971), pp. 50-52, and James Morgan, "The Anatomy of Income Distribution," Review of Economics and Statistics 44 (August, 1962), pp. 281-282.

${ }^{8}$ The U.S. estimate is taken from DavidI. Verway, "A Ranking of States by Inequality Using Census and Tax Data, "Review of Economics and Statistics 48 (August, 1966), p. 317.

9Niles P. Hansen, "Some Neglected Factors in American Development Policy: The Case of Appalachia, "Land Economics 42 (February, 1966), pp. $1-9$.

${ }^{10}$ See for example, John A. Kuehn and Jerry G. West, "Highways and Regional Development, "Growth and Change 2 (July, 1971), pp. 23-28. Also see John M. Munro, "Planning the Appalachian Development Highway System: Some Critical Questions," Land Economics 45 (May, 1969), pp. 149-161. 